قر اءات و مر اجعات

\title{
مسيرة المعرفة والمنهج في الفكر العربي الإسلامي \\ أنور الزعبي
}

\section{مراجعة: محمد سلاّم جميعان}

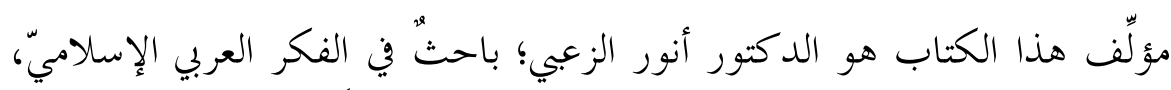

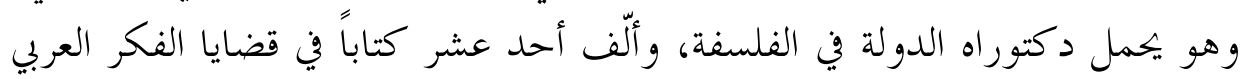

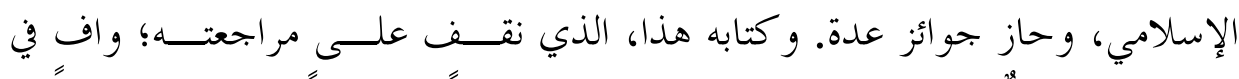

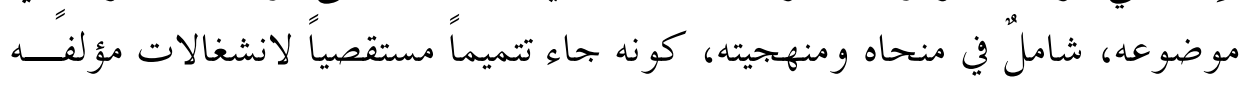

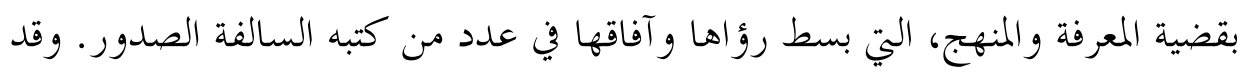

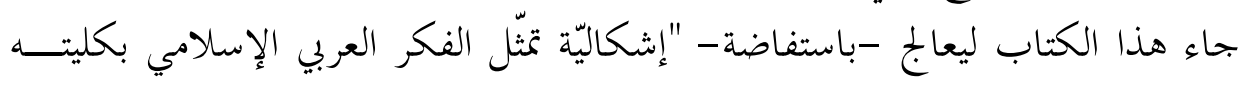
و وآفاقه."' هذاء '

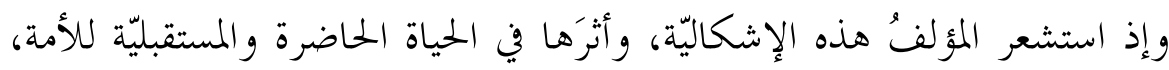

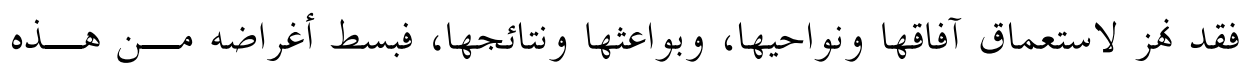

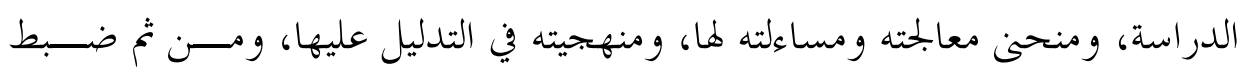

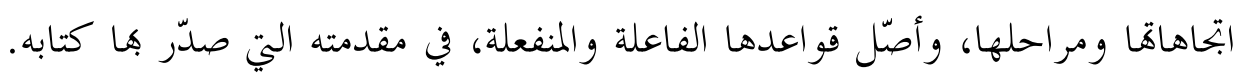

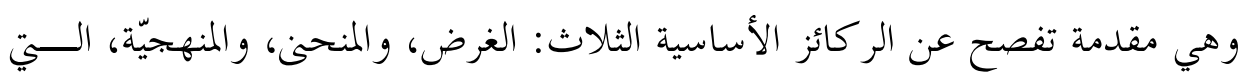

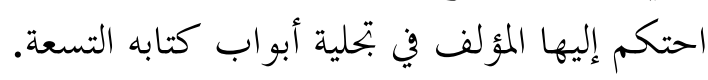

وتأتي أهميّة هذه الدراسة، من استيعاها واستجماعها للمسائل المتعددة التي عُيني هـا

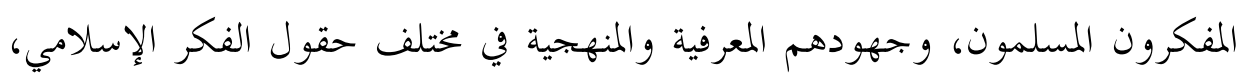

* الزبي، أنور . مسيرة المعرفة والمنهج في الفكر العربي الإسلامي، طا، عمان: المعهد العالمي للفكر الإسـلامي،

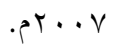

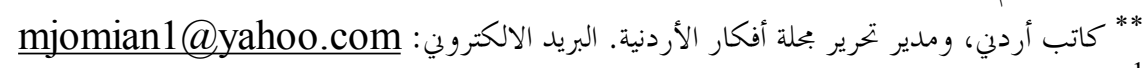

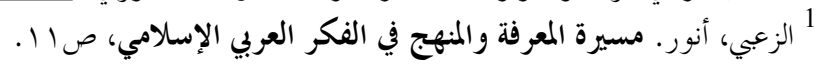


و مشتملاته من المعارف و العلوم، ومواطن اختلاف كل مفكر عن آخر، أو اتفاقـه، ؤه

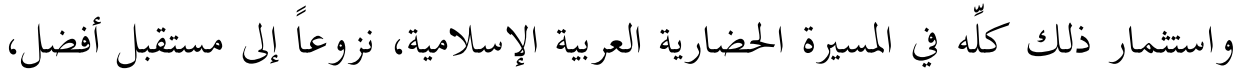
يأخذ في حسبانه تحوّلات العصر، و الحداثة و التحديث، ومن ثم استنباط المنهجية النقدية

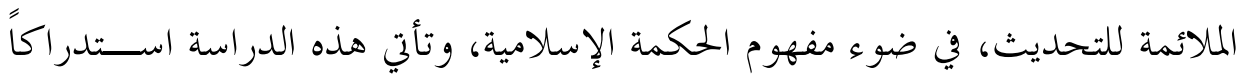

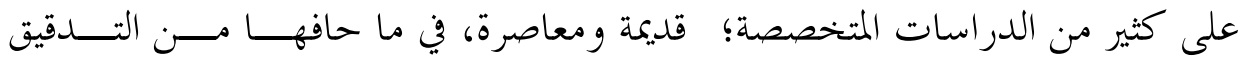
و التحقيق و العمق و الشمول، وهي العناصر التي استوفتها هذه الدراسة واستحضرقا في

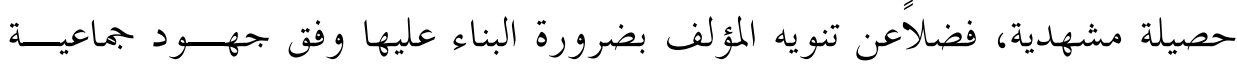
مؤ سسية.

يشكل الفصل الأول: (منهجية إعادة القراءة و النظم والاستشراف) مهاداً تأصيلياً

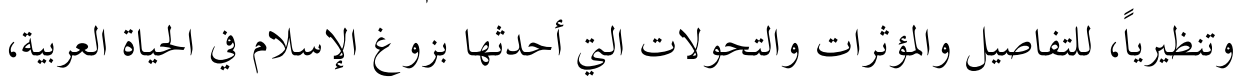

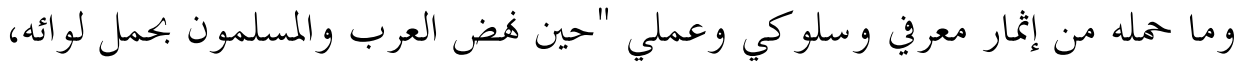

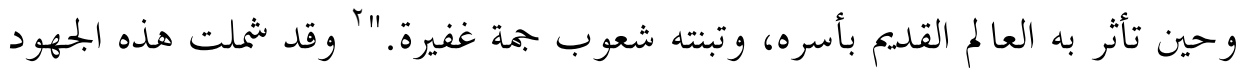

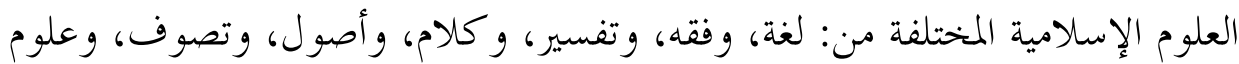

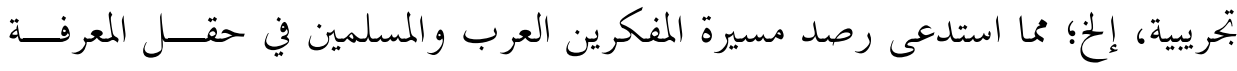

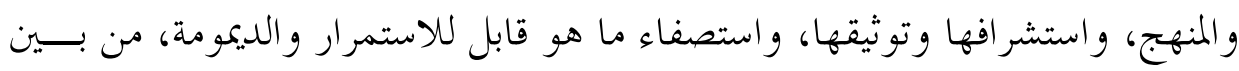

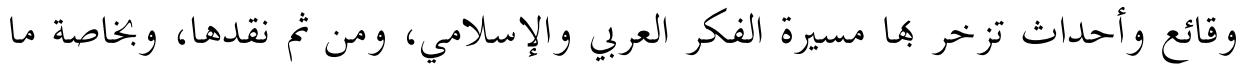

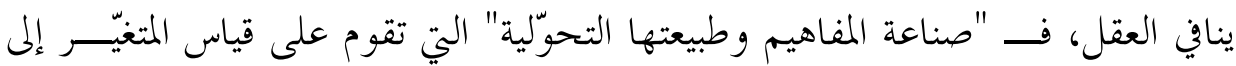

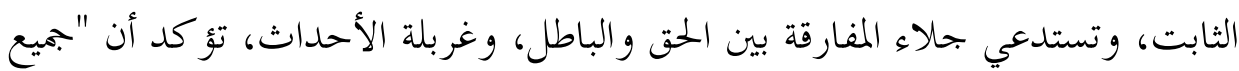

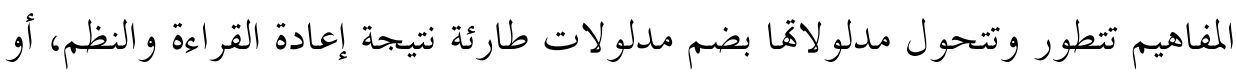

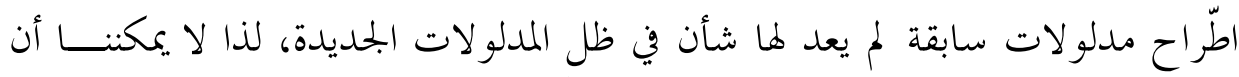

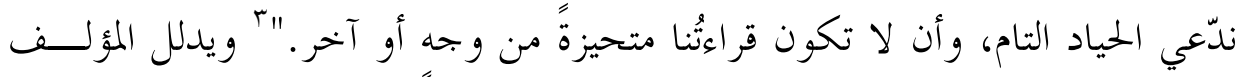

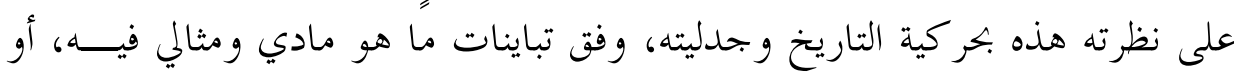
بدمج هاتين النظرتين، بعيداً عن الانغلاق وتمجيد الماضي، وإقرارًاً بالتأثير والتأثر.

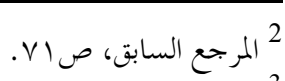

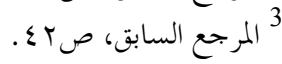


وفي السياق نفسه، يؤ كد المؤلف التطور الدلالي للألفاظ اللغوية، على الرغم من

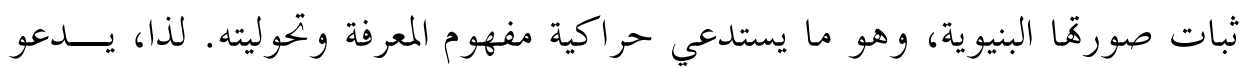

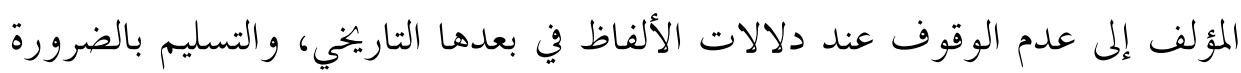

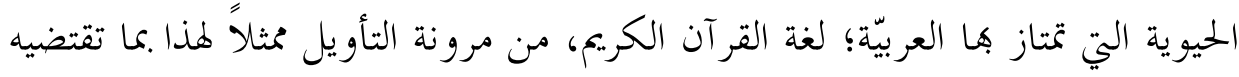

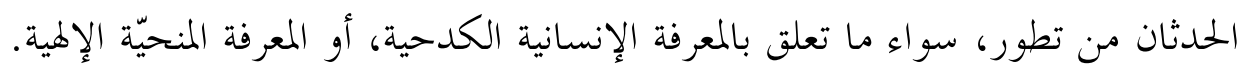
فثمة علاقة وطيدة بين الشريعة، والاجتهاد، والإبداع؛ لتحقيق الغايات المثلى للمعرفة.

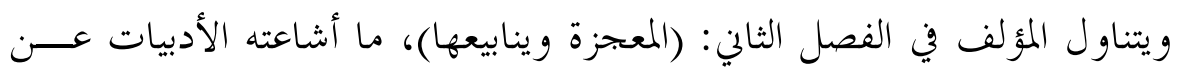

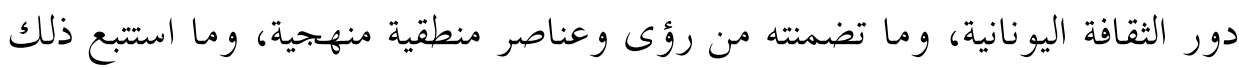

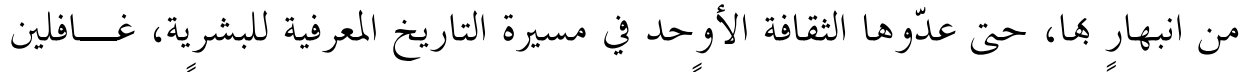

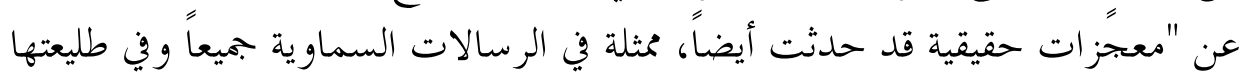

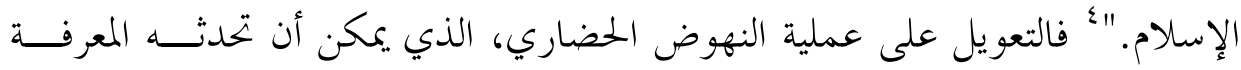

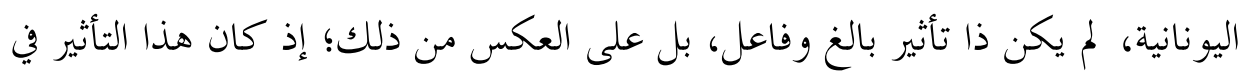

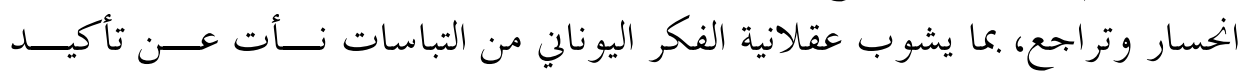

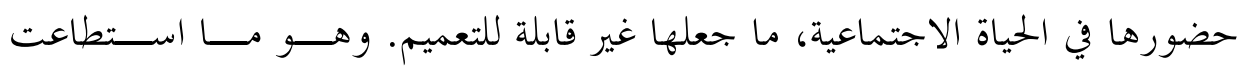

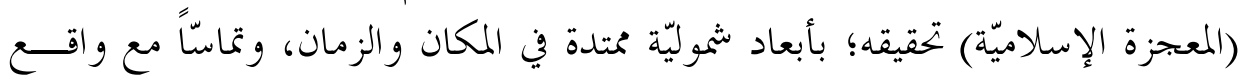

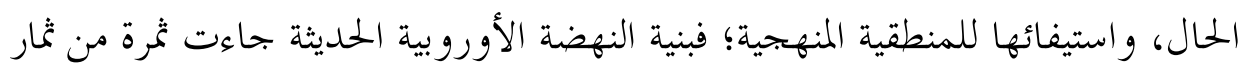

$$
\text { (المعجزة الإسلامية). }
$$

وينبّه المؤلف إلى ما شاب الحضارة اليونانية من أساطير وخرافات وألات وأضاليل، ينبغي

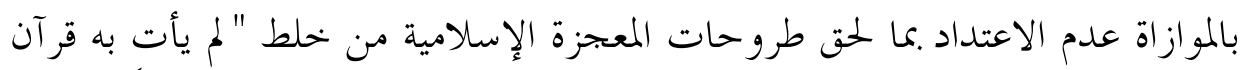

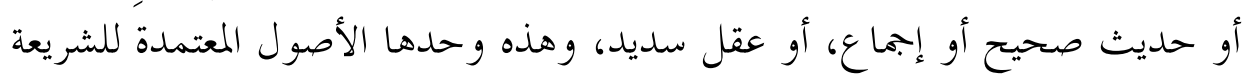

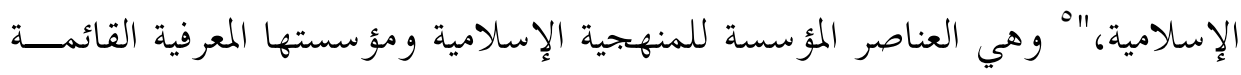
على عقلانية شاملة.

وفي سبيل استقصاء الشموليّة وعناصر الإثمار؛ لتحقيق الشهود الحضاري، يخلّـلـل

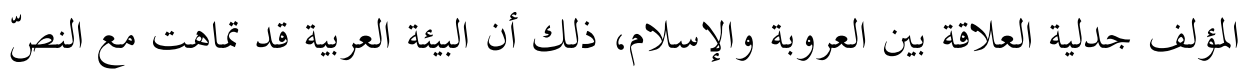

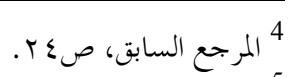

$$
\begin{aligned}
& 5 \text { المرجع السابق، صع ع . }
\end{aligned}
$$


الإلهيّ وتفاعلت معه، ما جعلها أمّة الدعوة، والحاضنة الأمينة -من خــلال إنــساها

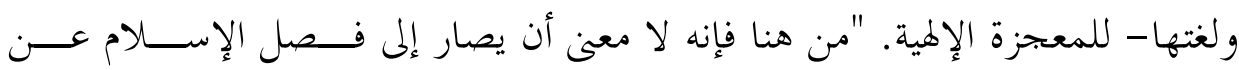

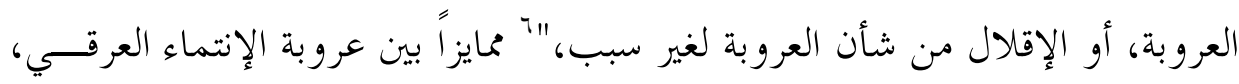

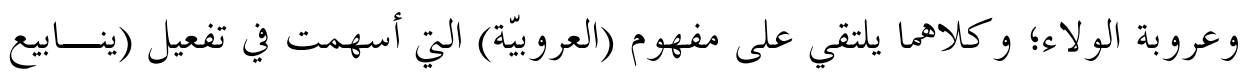

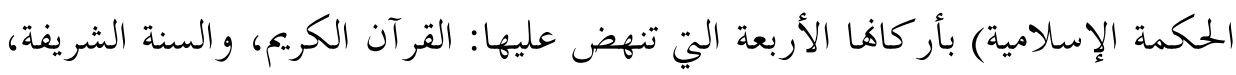

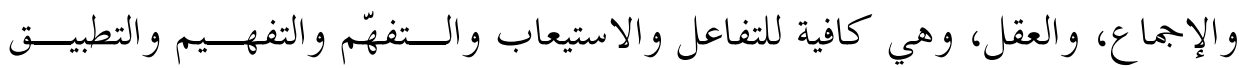

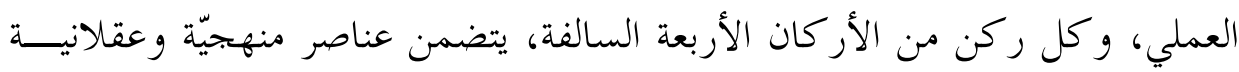

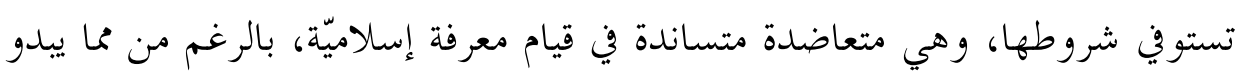
من إشكاليّة وقطيعة نسبية بين العقل والنقل، وهو ما تكفّل التأويلٌ بحلّها ولأْمها.

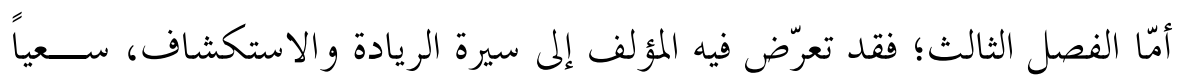

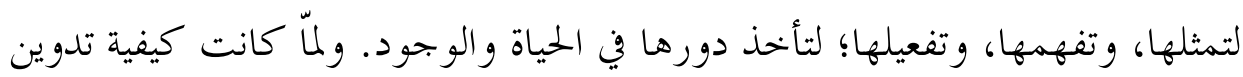

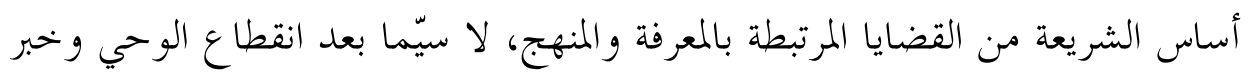

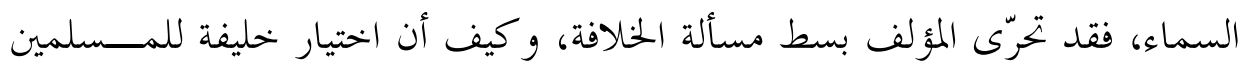

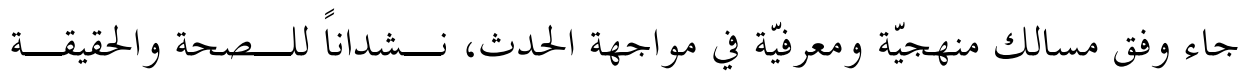

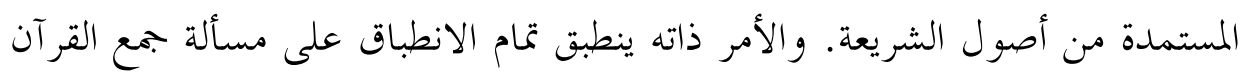

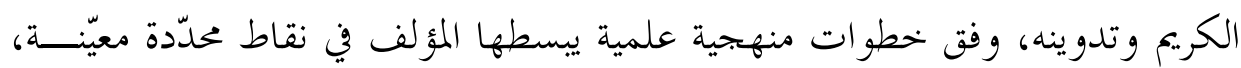

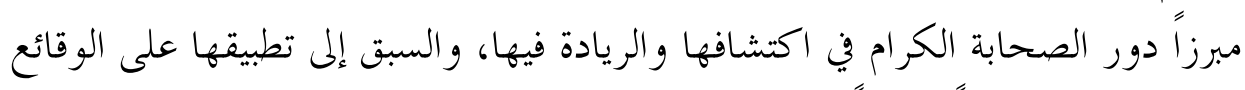

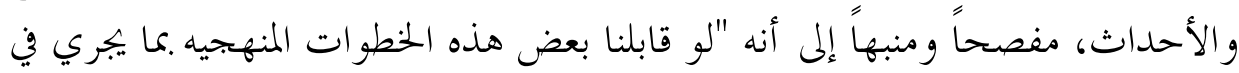

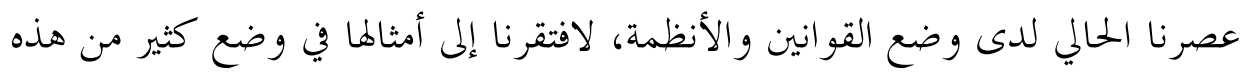

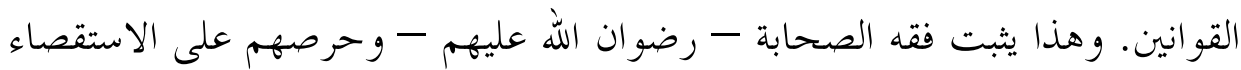

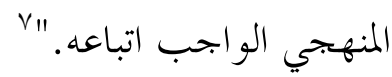

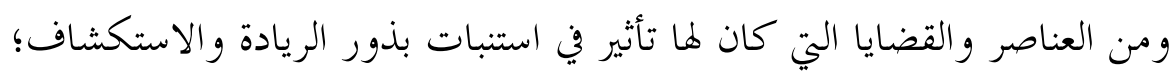

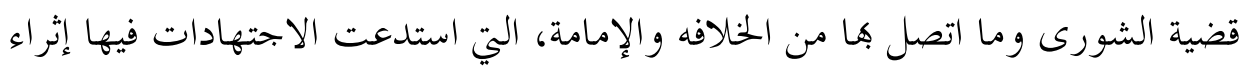

$$
\text { } 7 \text { المرجع السابق، صعابع. }
$$




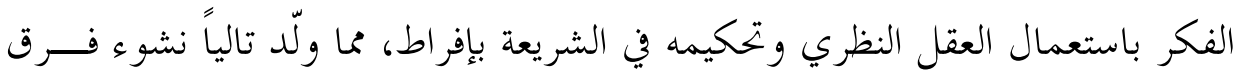

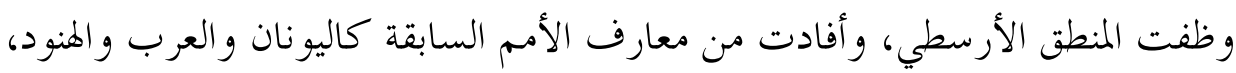

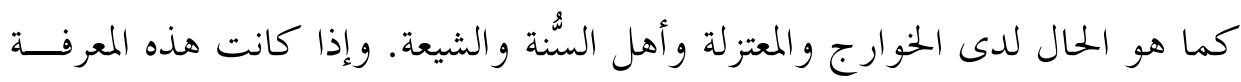

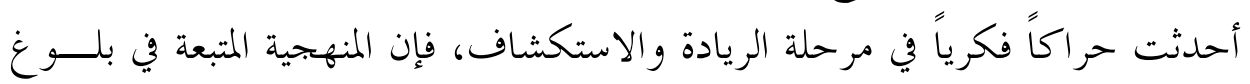

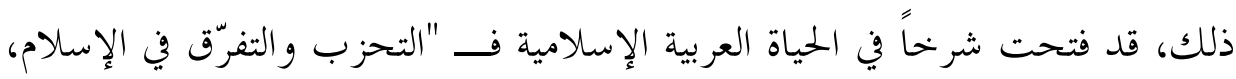

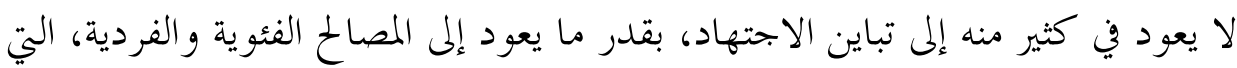

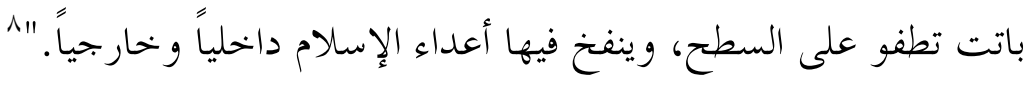

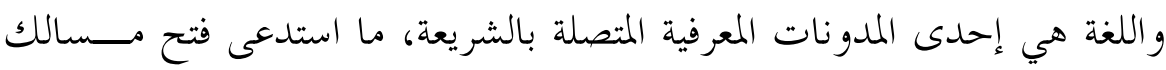

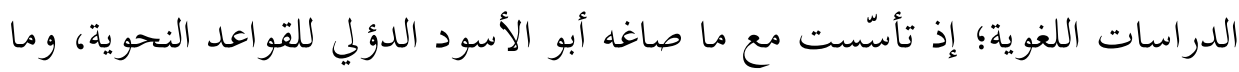

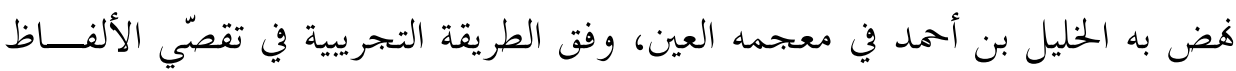

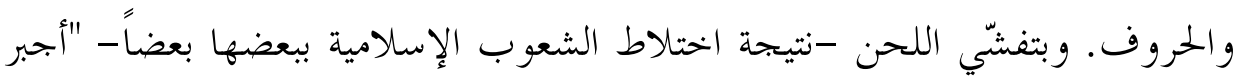

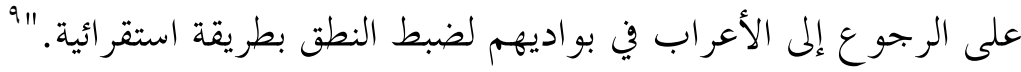

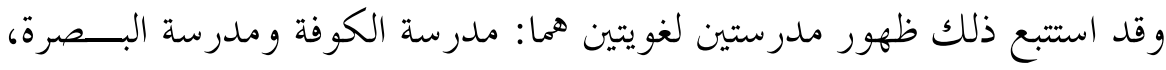

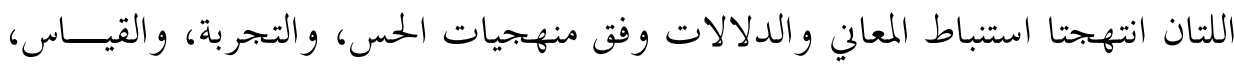

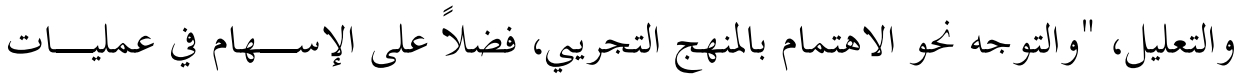

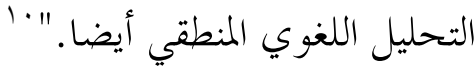

ولتلاحق الأحداث في الحياة الإسلامية، وفرضها تحســـلات جذريسـة في الحيــــاة

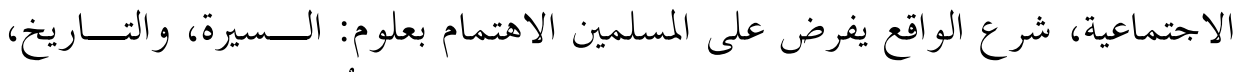

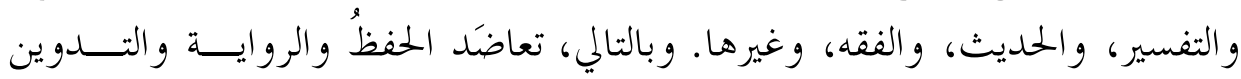

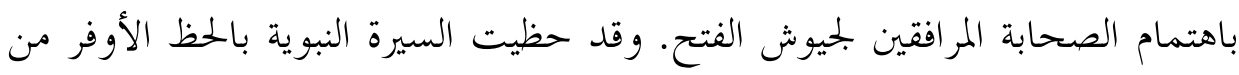

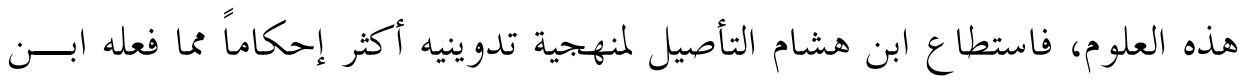

$$
\begin{aligned}
& 8 \text { المرجع السابق، صVV. }
\end{aligned}
$$

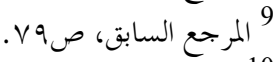

$$
\begin{aligned}
& 10 \text { المرجع السابق، صابق، صو. }
\end{aligned}
$$


إسحق، حتى أحكمها ابن حزم وابن خلدون، اللذان خلّصا "الروايات الصحيحة من

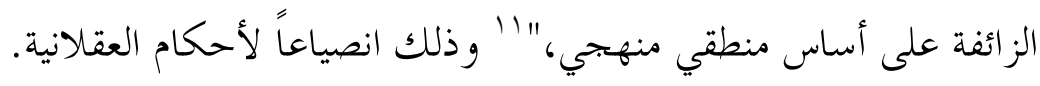

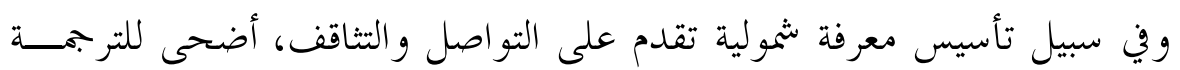

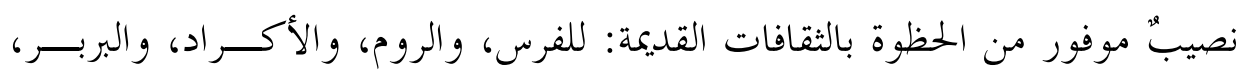

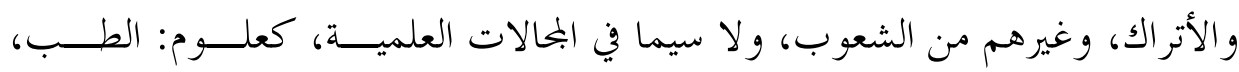

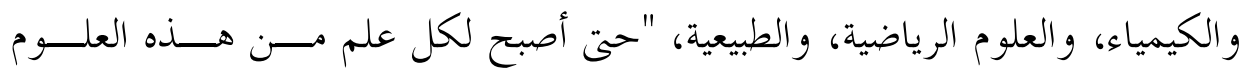

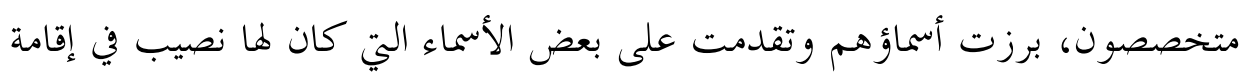

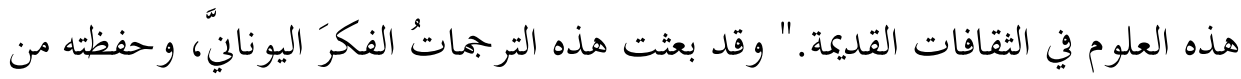
الاندثار و الموت.

في الفصل الرابع، عرض المؤلف لسيرة التفــتح والازدهــــار للعلــــوم الــشـرعية

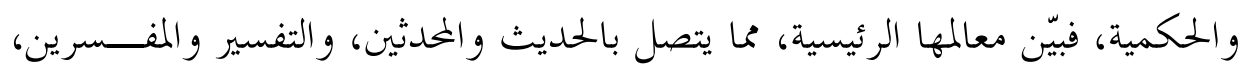

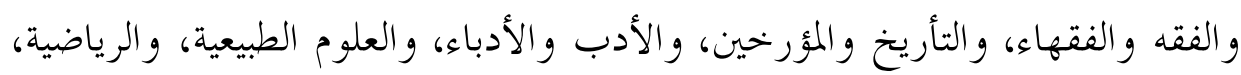

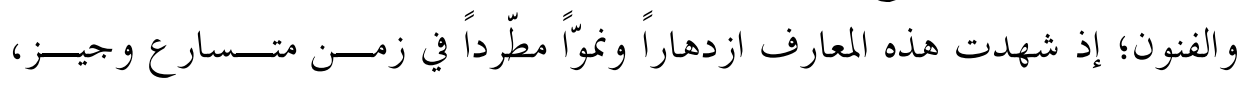

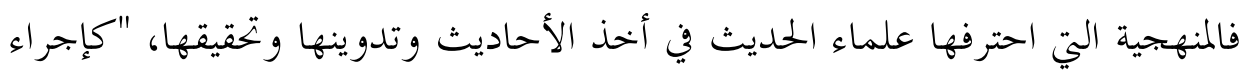

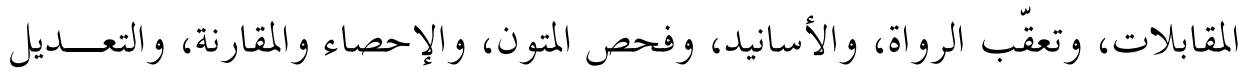

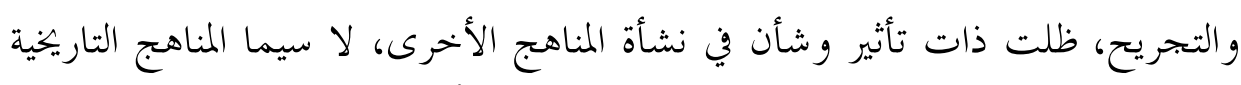

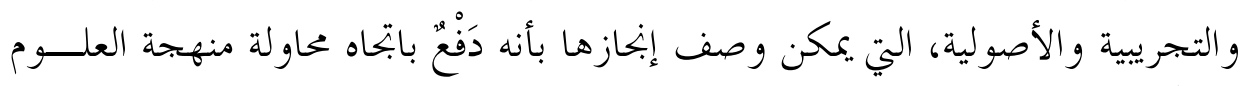

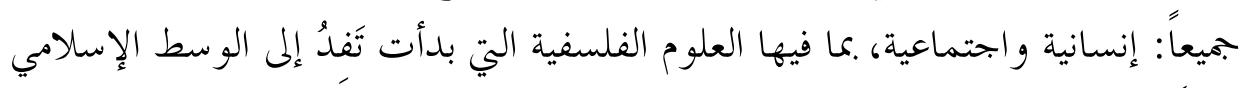

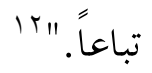

ويمثل المؤلف في العنوانات الفرعية التي تضمنها هذا الفصل، بوافر من الأعــلام

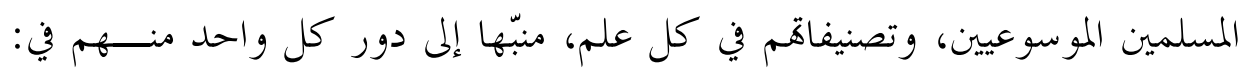

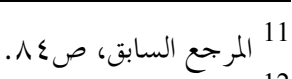

$$
\begin{aligned}
& 12 \text { المرجع السابق، صالمانو صن. }
\end{aligned}
$$


التأصيل، و التقعيد، والإضافة. و كلٌّ ذلك بتأثير من الشريعة، التي جعلـــت المعـــارف

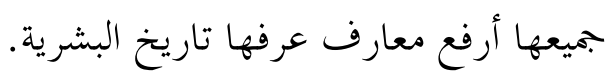

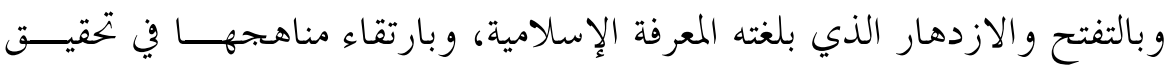

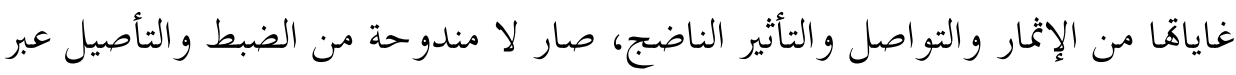

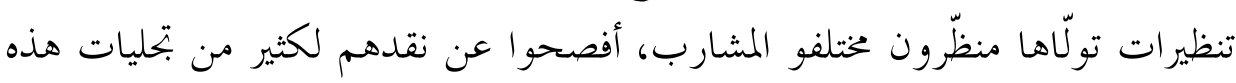

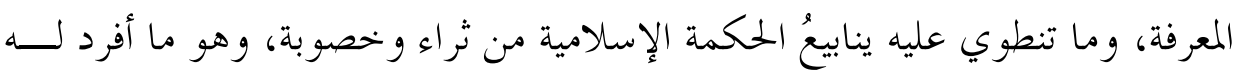

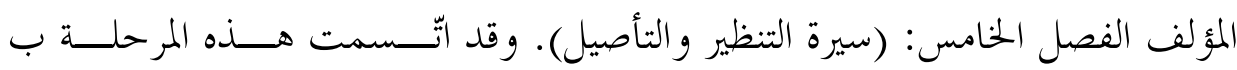

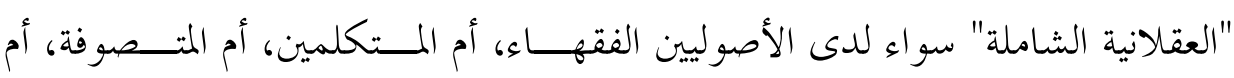

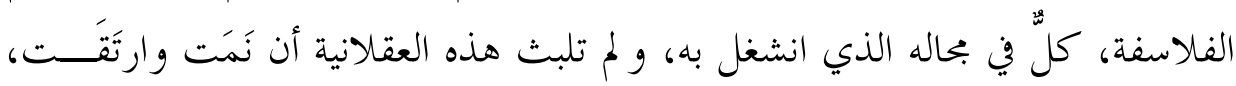

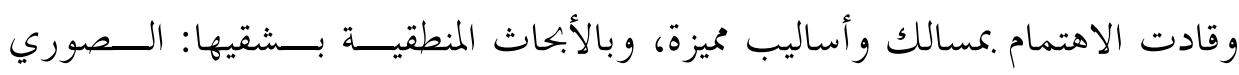

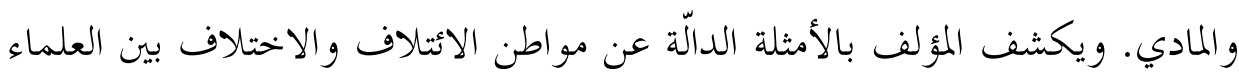

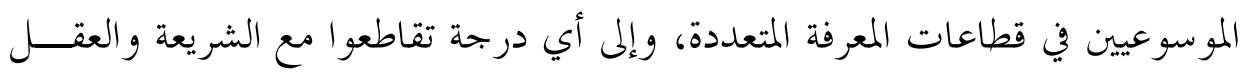
والثقافة اليونانية، والثقافات الأخرى الو افدة.

لكن المؤلف نفسه يستدرك بعنوان فرعي: (إشكاليات التنظير والتأصيل) و المتمثلة

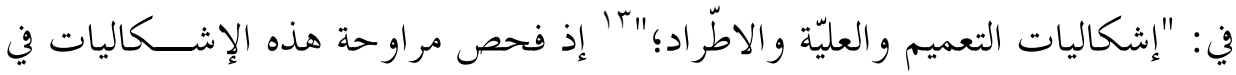

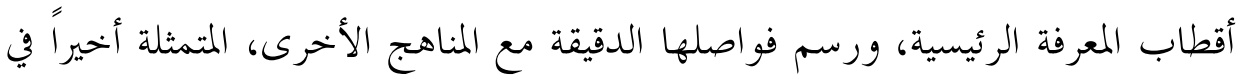

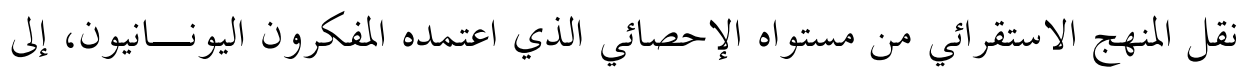
المستوى التجريي، ولا سيما في حقل العلوم الطبيعية والإنسانية.

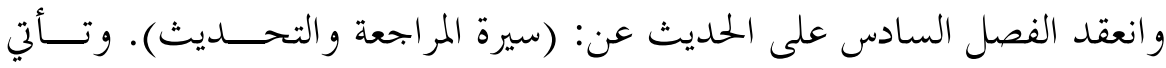

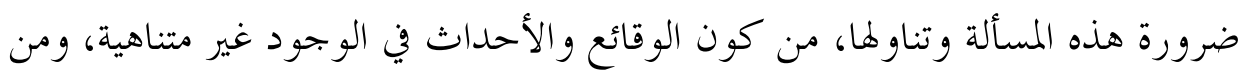

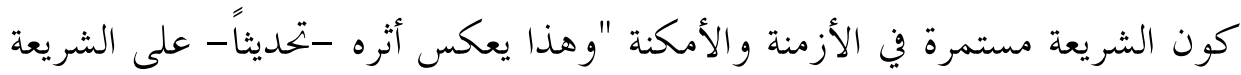

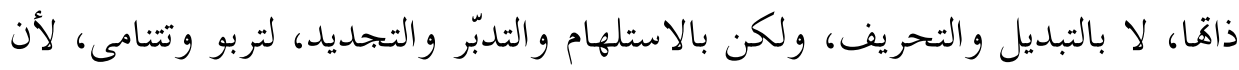


التجديد من قدر الله."اء" وتغدو عملية المراجعة والتحديث ضرورة لازمـــة عنـــدما

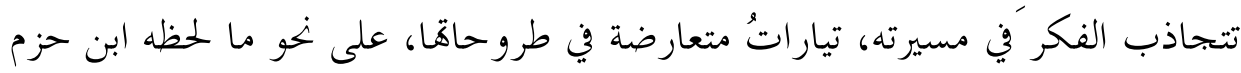
من تصادم بين تيار الفكر السلفي المضض، والتيار الفكري المنتسب للتغريب، فيما كان ينبغي أن يسيرا متصالحين، وهو ما بحلّى في كتابه (الإحكام في أصول الأحكام) وطبّقه وينه

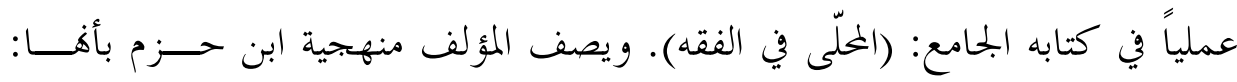

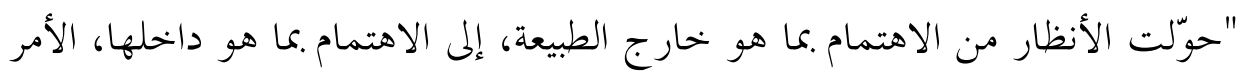

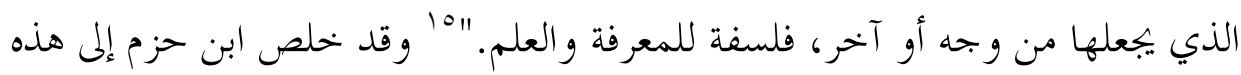

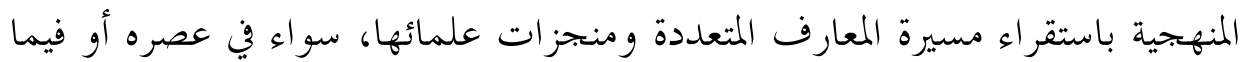

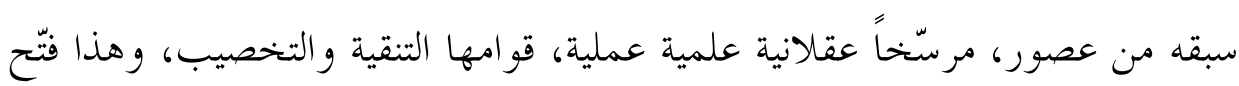

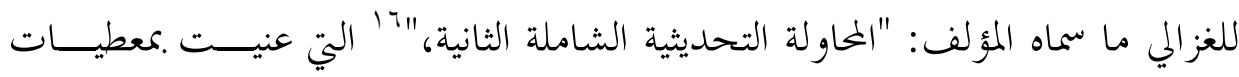

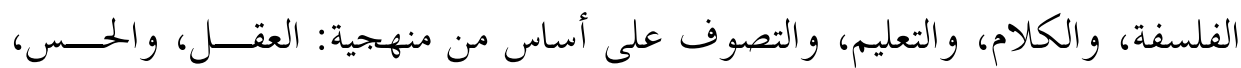

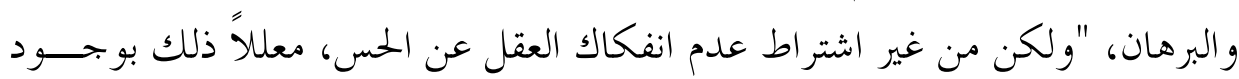

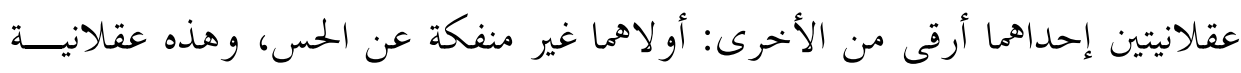

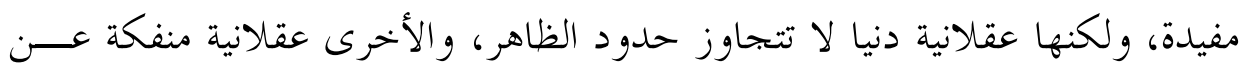

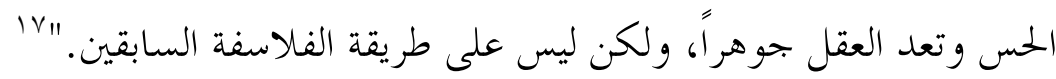

و بالرغم من نقاط الافتراق و الالتقاء مع منهجية ابن حزم وطروحاتــه، إلا أنــــ

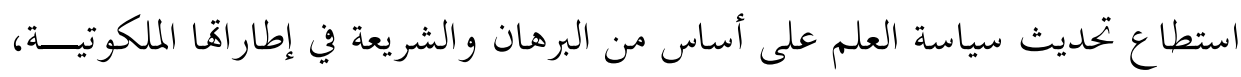

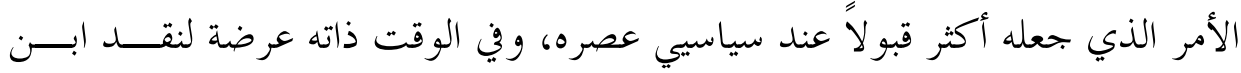

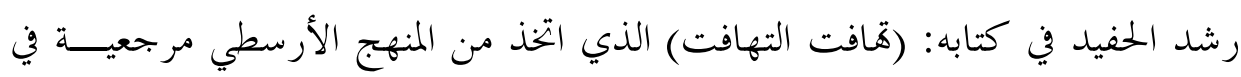

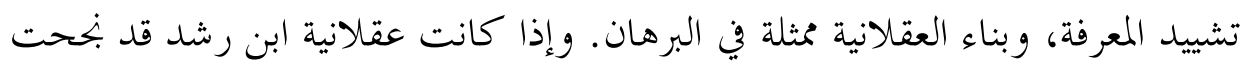

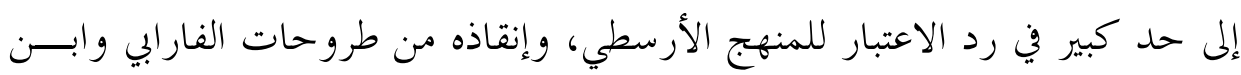

$$
\begin{aligned}
& 14 \text { 15 المرجع السابق، ص100. }
\end{aligned}
$$

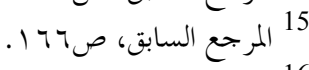

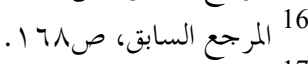

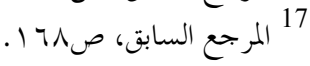


سينا، فإن جهوده التحديثية قد جوهت بالمصادرة وحرق كتبه، كون طروحاته لم تحظ

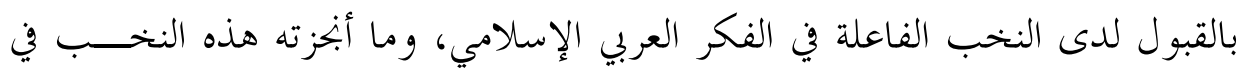
مسيرة العقلانية المنهجية العربية الإسلامية الخالصة.

وهنا يسترسل المؤلف في الحديث عن واقعية ابن تيمية، وتوفيقها بين أســلوبين

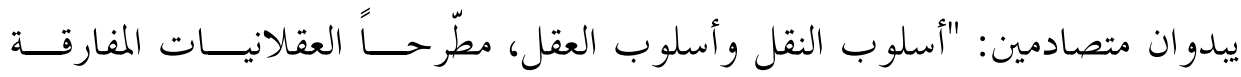

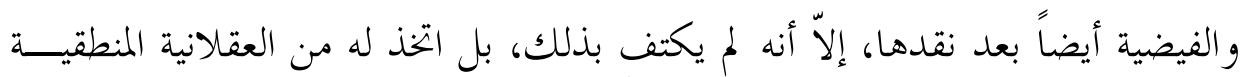

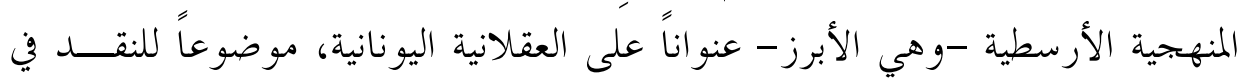

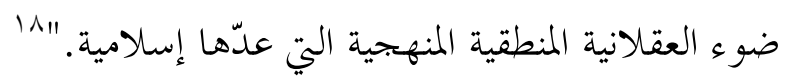

و يفيض المؤلف في استخلاص واقعية ابن تيمية، وأُسسها التي بُنيت عليها، وقدرته

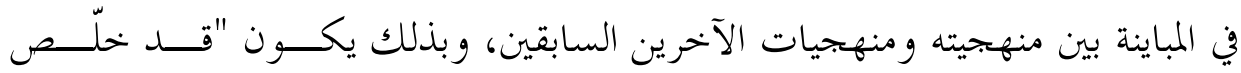

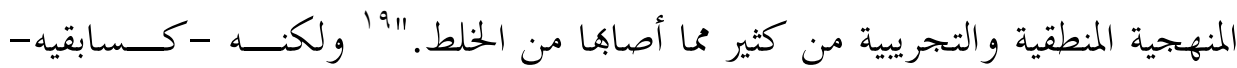

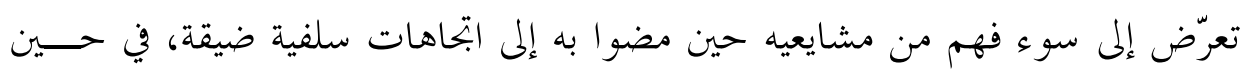
ذهب خصومه إلى تجريمه وبحريحه، "وبصرف النظر عن عن بعض التوجهات التي سار فيها،

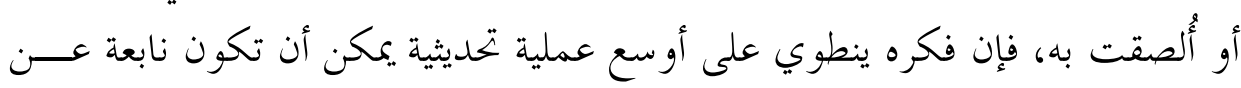

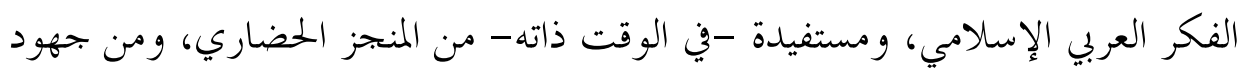

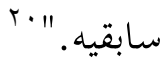

ويصرّح المؤلف أن العقلانية المنهجية التي انتهجها ابن خلدون، لا تختلف كــثيراً

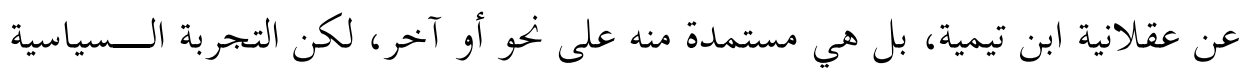

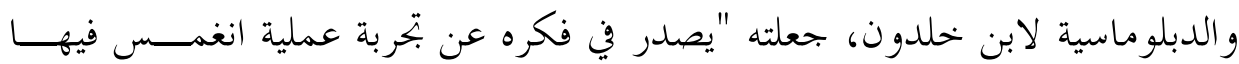

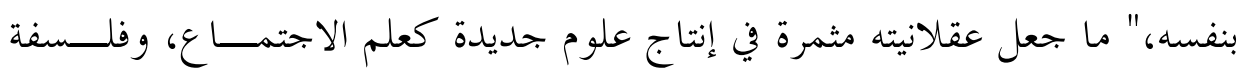

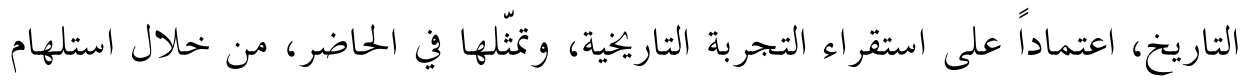

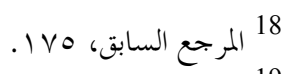

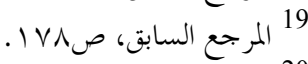

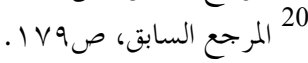


المعارف السابقة كلها، وعرض إبنحازات التجربة العربية الإسلامية، ما يؤكد الـــوعي

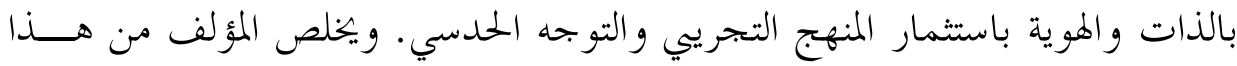

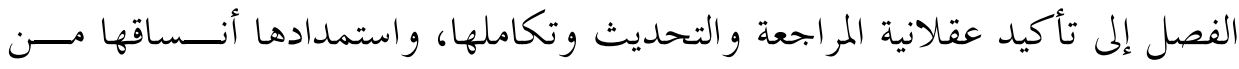

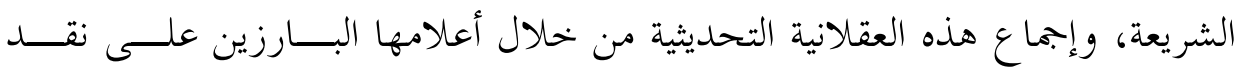

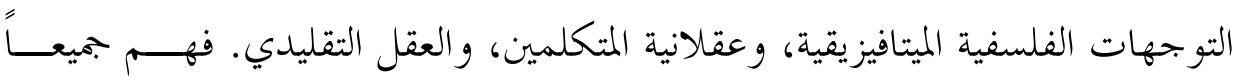

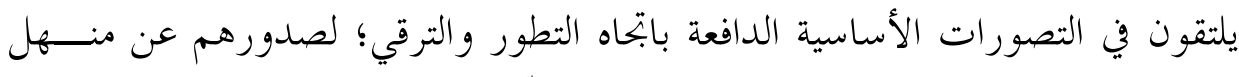

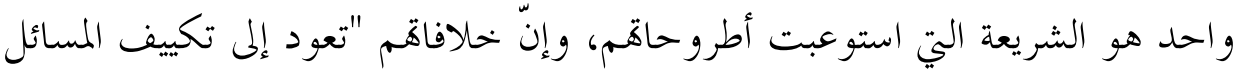

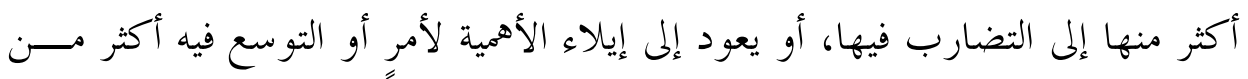
غيره."

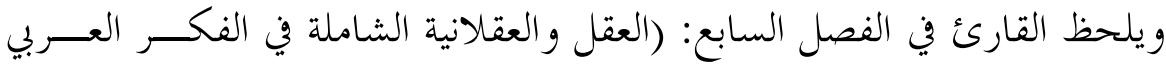

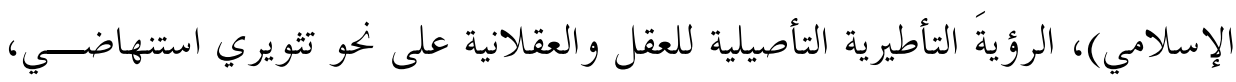

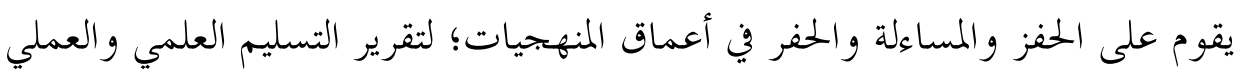

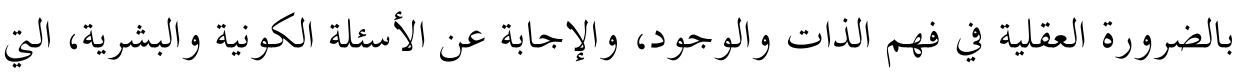

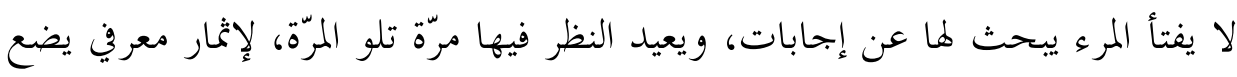

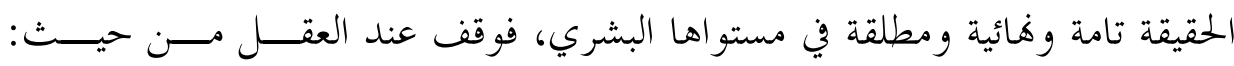

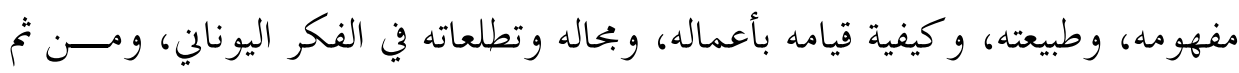

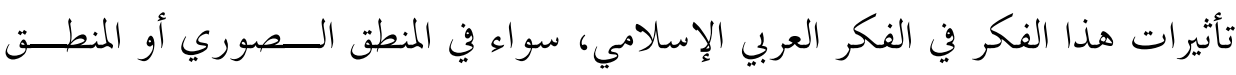
المادي.

وفي فورة الإقرار بأن الوجود ليس حالة قارّة، وسعي الإنسان إلى تلبية احتياجاته

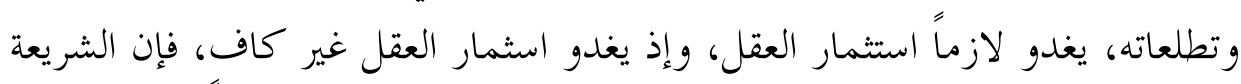

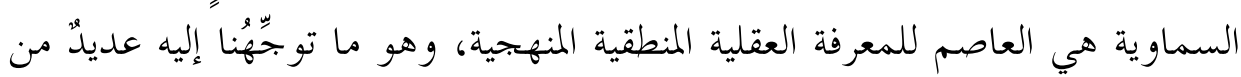

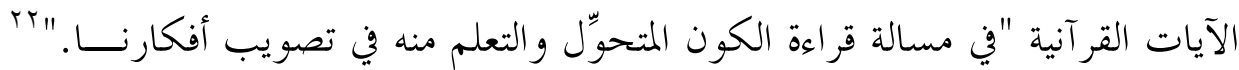

$$
22 \text { 221 المرجع السابق، صلو 19. }
$$




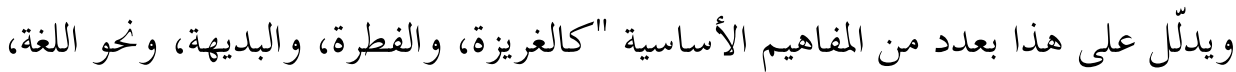

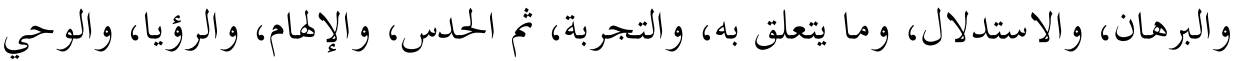

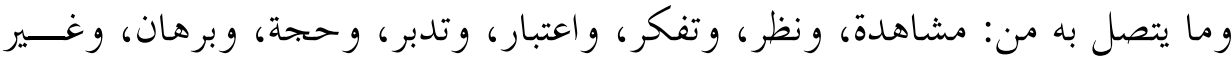

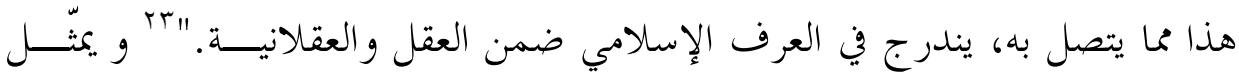

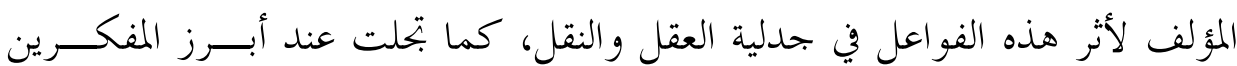

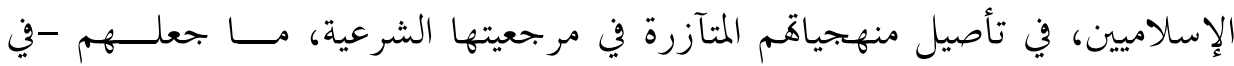

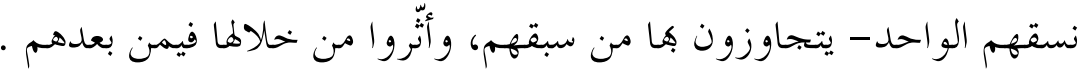

ويخصص المؤلف الفصل الثامن للحديث عن (سيرة التراجع و النكوص)، ويعيــــ

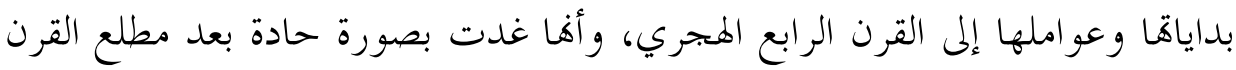

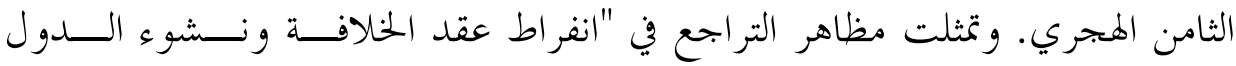

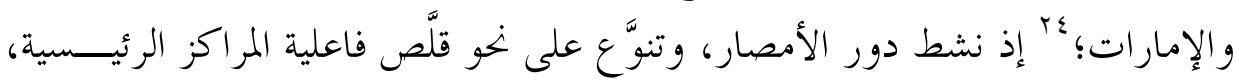

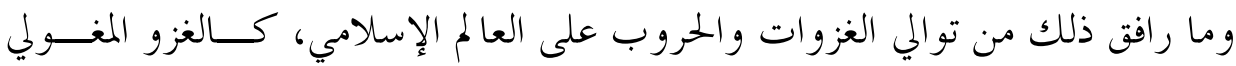

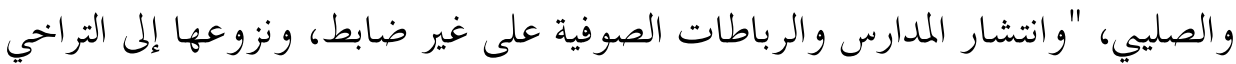

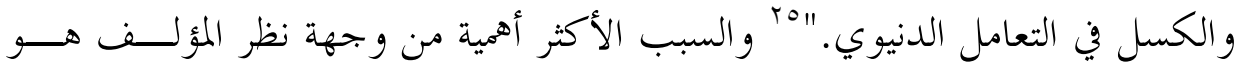

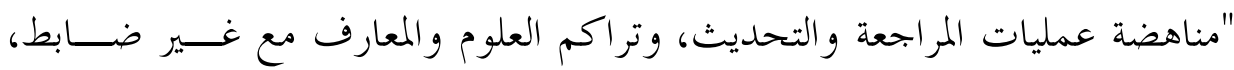

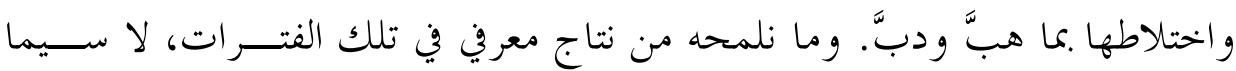

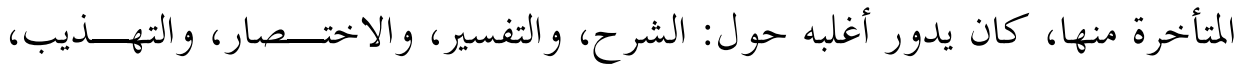

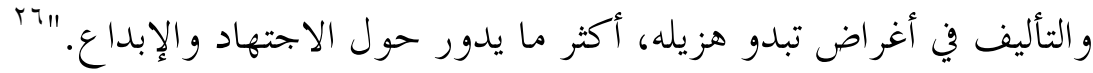

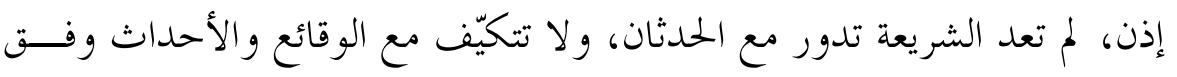

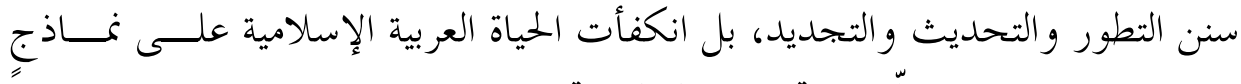

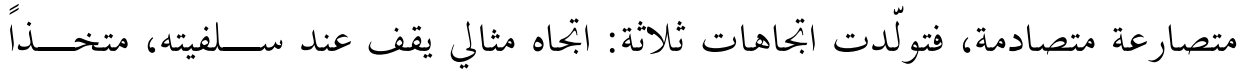

$$
\begin{aligned}
& 23 \text { المرجع السابق، صV •r. }
\end{aligned}
$$

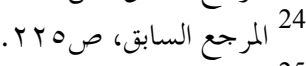

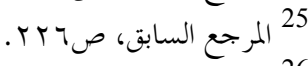

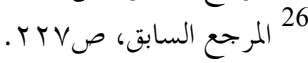


الماضي درعاً يحمي به ذاته ورسالته، واتحاه تغريي يدعو إلى الانفلات من صــالاحية

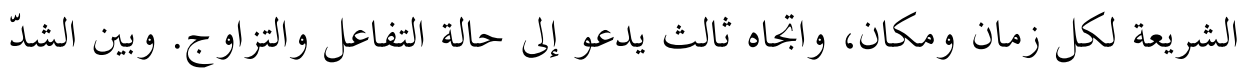

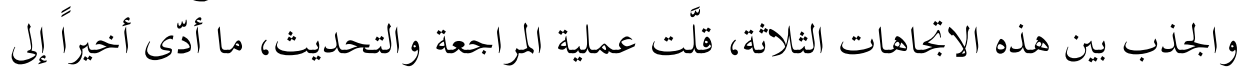

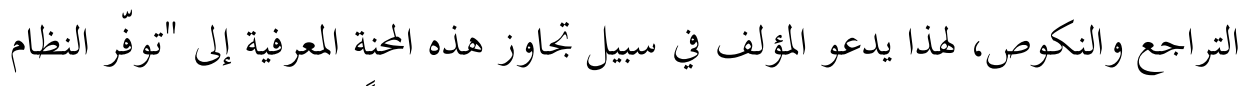

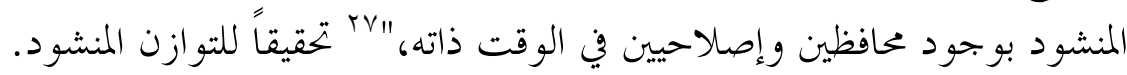

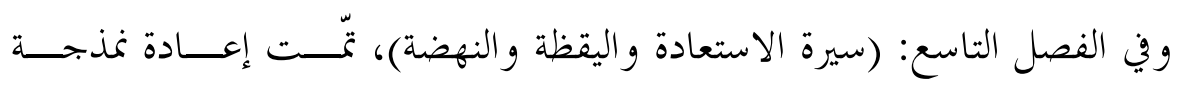

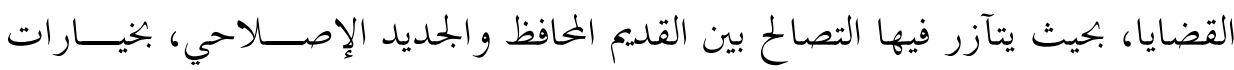

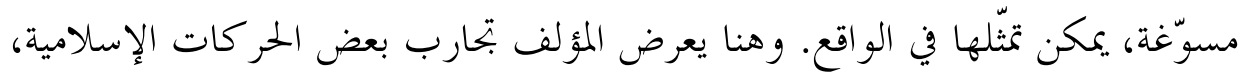

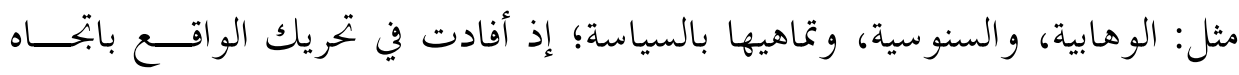

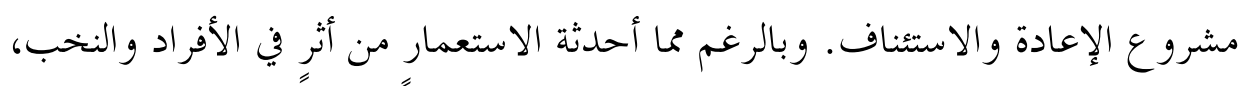

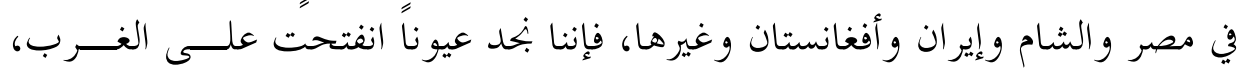

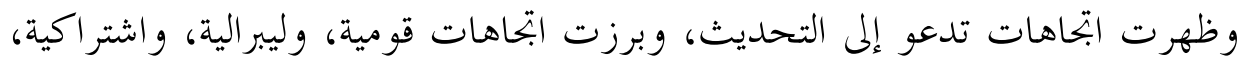

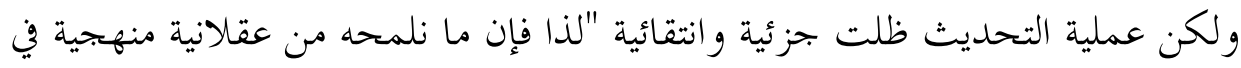

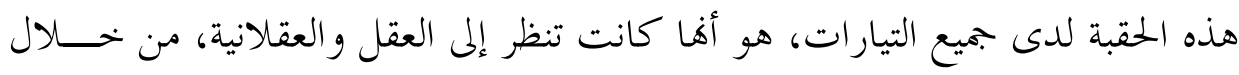

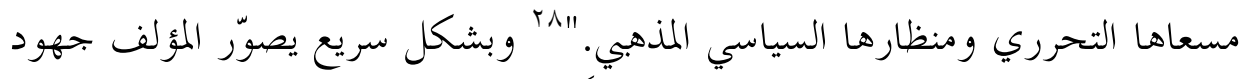

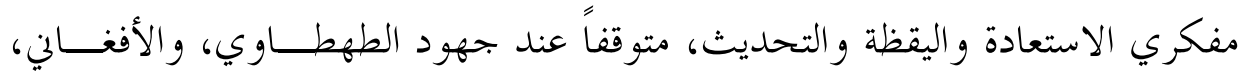

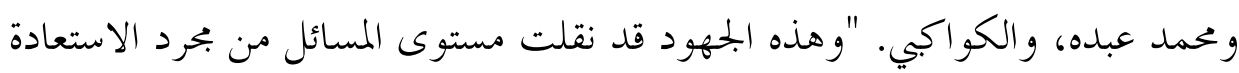

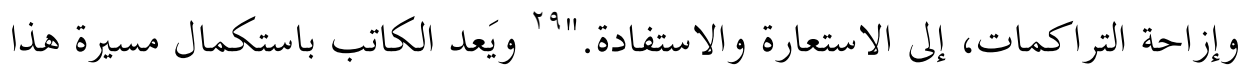

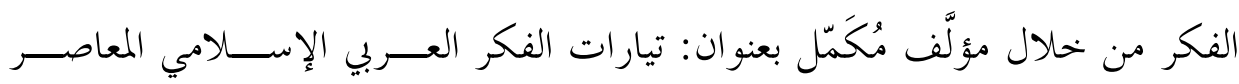
وتحولات العصر وتداعياته، آملين له التوفيق.

$$
\begin{aligned}
& 27 \text { المرجع السابق، صبr Trك. }
\end{aligned}
$$

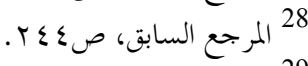

$$
\begin{aligned}
& 29 \text { المرجع السابق، صرابق صعابع. }
\end{aligned}
$$

